\title{
Ovarian Dermoid Cyst with Secondary Tumor
}

National Cancer Institute

\section{Source}

National Cancer Institute. Ovarian Dermoid Cyst with Secondary Tumor. NCI Thesaurus.

Code C7284.

An adult-type tumor that has derived from an ovarian dermoid cyst. Representative examples include dermoid cyst with secondary carcinoma, dermoid cyst with secondary sarcoma, and dermoid cyst with pituitary-type tumor. 